Acta Crystallographica Section F

Structural Biology

and Crystallization

Communications

ISSN 1744-3091

\section{Xiang $\mathrm{Xu},{ }^{\text {a,b }}$ Xiaoai Zhang, Guangwen Lu $u^{b}$ and Yongping $\mathrm{Cai}^{\mathrm{a} *}$}

${ }^{a}$ College of Life Science, Anhui Agricultural University, Anhui 230036, People's Republic of China, and ${ }^{\mathbf{b}} \mathrm{CAS}$ Key Laboratory of Pathogenic Microbiology and Immunology, Institute of Microbiology, Chinese Academy of Sciences, Beijing 100101, People's Republic of China

Correspondence e-mail: swkx12@ahau.edu.cn

Received 21 March 2012

Accepted 15 June 2012

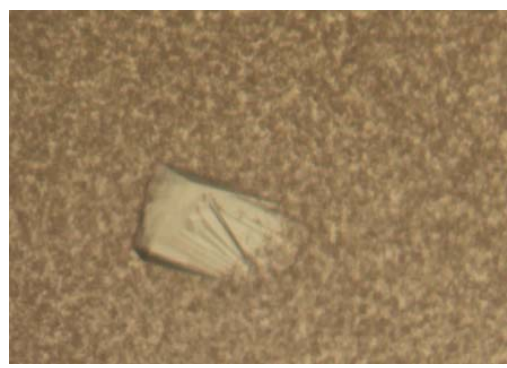

(C) 2012 International Union of Crystallography All rights reserved

\section{Purification, crystallization and preliminary X-ray analysis of the IgV domain of human nectin-4}

Nectin-4 belongs to a family of immunoglobulin-like cell adhesion molecules and is highly expressed in cancer cells. Recently, nectin- 4 was found to be a receptor of measles virus and the $\mathrm{IgV}$ domain sustains strong binding to measles virus $H$ protein. In this study, the successful expression and purification of human nectin-4 $\mathrm{V}$ domain (nectin-4v) is reported. The purified protein was crystallized using the sitting-drop vapour-diffusion method. The crystals diffracted to $1.8 \AA$ resolution and belonged to space group $P 2_{1}$, with unit-cell parameters $a=33.1, b=51.7, c=56.9 \AA$, $\beta=94.7^{\circ}$. Preliminary analysis of the diffraction data was also performed.

\section{Introduction}

Nectins are cell adhesion molecules (CAMs) that belong to the immunoglobulin superfamily and play essential roles in $\mathrm{Ca}^{2+}$ independent intracellular interactions (Takahashi et al., 1999). The nectin family has four members: nectin-1, nectin-2, nectin-3 and nectin-4 (Takai \& Nakanishi, 2003). In addition, five molecules named nectin-like $(\mathrm{Necl})$ with domain structures similar to those of nectins have also been discovered. Both nectin and nectin-like molecules have an extracellular region with three immunoglobulinlike (Ig-like) domains (one V domain and two C2 domains; VCC), a single transmembrane region and a cytoplasmic tail region (Takai et $a l ., 2003)$. The major difference between nectins and Necls is that the former can associate with afadin, an F-actin-binding protein, through their conserved C-terminal motif, while the latter cannot form any such association (Fuchs \& Colonna, 2006). All members of the nectin family have two or three splicing variants, i.e. nectin- $1 \alpha$, nectin- $1 \beta$, nectin- $1 \gamma$, nectin- $2 \alpha$, nectin- $2 \delta$, nectin- $3 \alpha$, nectin- $3 c$ and nectin- $3 \gamma$ isoforms exist. Nectin-1, nectin-2 and nectin-3 are widely expressed in a variety of cells, including epithelial cells, neurons and fibroblasts. Nectin-2 and nectin-3 are also expressed in cells that lack cadherins, such as monocytes, spermatids and B cells (Takai \& Nakanishi, 2003).

While nectin-1, nectin-2 and nectin-3 have been intensively studied, work on nectin- 4 has been relatively rare. Based on the results of Takai et al. (2008), two splicing variants of nectin-4 exist, with the shorter one lacking amino acids 412-436. Like the other members of the nectin family, nectin-4 is involved in cell-cell adhesion by forming a homodimer or a heterodimer with nectin-1. Initially, human nectin-4 was mainly detected in the placenta (Reymond et al., 2001), but recent research has shown that nectin-4 is also highly expressed in cancer cells such as lung cancer, breast cancer and ovarian cancer cells (Fabre-Lafay et al., 2007; Takano et al., 2009; Derycke et al., 2010). As early detection of cancer is difficult owing to a lack of specific and effective tests, the potential use of nectin- 4 as a cellular marker of cancer should be considered (Derycke et al., 2010). In addition, a recent report showed that nectin- 4 can support measles virus entry and lateral spread of the virus in well differentiated primary human airway epithelial sheets (Mühlebach et al., 2011). The high expression of nectin-4 in cancer cells and its strong specificity for measles virus are also suggestive of a potential function of nectin-4 in oncolysis (Noyce et al., 2011). Therefore, as an important member of the nectin family, nectin- 4 deserves further study of its structural features and cellular functions. 
Several studies have demonstrated that viruses utilize the $\operatorname{IgV}$ domain of nectin or Necl molecules as the authentic binding entity (Zhang et al., 2008, 2011). The IgV domain of nectin-4 plays a critical role in cell adhesion and measle virus entry. Accordingly, the work of Mühlebach et al. (2011) has shown that the IgV domain of nectin-4 sustains strong binding to measles virus $\mathrm{H}$ protein. Thus, a highresolution crystal structure of the $\mathrm{V}$ domain of nectin-4 (nectin-4v) should supply valuable information on the possible interaction between nectin- 4 and measles virus, thereby facilitating future modelling studies and structure-directed drug design. In the present study, we report the successful expression, purification and crystallization of the nectin- $4 \mathrm{v}$ protein. A data set was collected to $1.8 \AA$ resolution using synchrotron radiation. Preliminary analysis of the diffraction data revealed a Matthews coefficient of $1.89 \AA^{3} \mathrm{Da}^{-1}$ and an estimated solvent content of about $35.0 \%$ for the crystal, with two nectin-4v molecules per asymmetric unit.

\section{Materials and methods}

\subsection{Subcloning}

The construction of the expression plasmid followed the canonical subcloning strategy. In brief, the DNA fragment encoding the $\mathrm{V}$ domain of human nectin-4 (nectin-4v; amino acids 32-145; gene accession No. NM_030916) was generated by PCR from PVRL4pENTR221 (purchased from GeneCopoeia) using the following specific primer pair: 5'-GGAATTCCATATGGGCGAACTGGAAACCTCAGACGTG-3' (forward) and 5'-CCGCTCGAGCACTCGGAGCCGCAGCCGCGC-3' (reverse). The amplified product was then inserted into the $N d e I$ and $X h o I$ restriction sites of the pET-21a expression vector (Novagen, Darmstadt, Germany). The recombinant protein expressed from this vector contains an extra methionine residue (from the initial codon) at the $\mathrm{N}$-terminus and additional leucine and glutamic acid residues (encoded by the XhoI sequence) and a hexahistidine tag at the $\mathrm{C}$-terminus. The recombinant plasmid was transformed into DH5 $\alpha$ (Novagen, Darmstadt, Germany) for plasmid amplification and was then verified by PCR, double enzyme digestion and direct DNA sequencing (GENEWIZ, Beijing, People's Republic of China).

\subsection{Expression and purification}

The verified recombinant plasmid was transformed into Escherichia coli BL21 (DE3) cells and grown at $310 \mathrm{~K}$ overnight on a LuriaBertani (LB) agar plate containing $100 \mu \mathrm{g} \mathrm{ml}^{-1}$ ampicillin. A single colony was inoculated into $50 \mathrm{ml} \mathrm{LB}$ medium containing $100 \mu \mathrm{g} \mathrm{ml}^{-1}$ ampicillin and incubated overnight. $20 \mathrm{ml}$ of the preculture was then transferred into 21 of fresh LB medium supplemented with ampicillin and grown at $310 \mathrm{~K}$. When the culture density $\left(\mathrm{OD}_{600}\right)$ reached approximately 0.6 , isopropyl $\beta$-D-1-thiogalactopyranoside (IPTG; Sigma, Beijing, People's Republic of China) was added to the cell culture to a final concentration of $0.1 \mathrm{~m} M$ and the cells were induced for $18 \mathrm{~h}$ at $289 \mathrm{~K}$. The nectin- $4 \mathrm{v}$ protein was expressed in soluble form with a C-terminal hexahistidine tag. The cells were harvested by centrifugation at $5000 \mathrm{~g}$ for $10 \mathrm{~min}$ at $277 \mathrm{~K}$ and were resuspended in

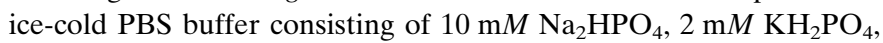
$2.7 \mathrm{~m} M \mathrm{KCl}, 137 \mathrm{~m} M \mathrm{NaCl} \mathrm{pH}$ 7.4. The cell pellet was disrupted using an ultrasonic cell crusher.

Cell debris was removed by centrifugation at $15000 \mathrm{~g}$ for $30 \mathrm{~min}$ at $277 \mathrm{~K}$. The crude protein extract was filtered through a $0.22 \mu \mathrm{m}$ low-protein-binding membrane and loaded onto a $5 \mathrm{ml}$ HisTrap HP column (GE Healthcare, Beijing, People's Republic of China) equilibrated with PBS buffer at $277 \mathrm{~K}$. The column was washed with five column volumes of buffer $A(20 \mathrm{~m} M$ Tris- $\mathrm{HCl} \mathrm{pH} 8.0,50 \mathrm{~m} M \mathrm{NaCl})$ and the protein was eluted at room temperature with a gradient of $0-100 \%$ buffer $B(20 \mathrm{~m} M$ Tris- $\mathrm{HCl} \mathrm{pH} 8.0,50 \mathrm{mM} \mathrm{NaCl}, 400 \mathrm{~m} M$ imidazole) using an ÄKTAexplorer system (GE Healthcare, Beijing, People's Republic of China). Fractions containing the target protein were collected and applied onto a HiLoad 16/60 Superdex 75 column (GE Healthcare) at room temperature to further remove aggregates and impurities. For molecular-weight (MW) calculations, the Superdex column was calibrated in advance using the Low Molecular Weight (LMW) calibration kit (GE Healthcare) containing five standard proteins of MWs in the range 6500-75000 Da. The purified nectin- $4 \mathrm{v}$ protein was concentrated by centrifugation at $277 \mathrm{~K}$ using an Amicon Ultra-15 centrifugal filter device (3 kDa cutoff; Millipore, Beijing, People's Republic of China). The protein buffer was then exchanged to $10 \mathrm{~m} M$ Tris- $\mathrm{HCl}, 10 \mathrm{mM} \mathrm{NaCl} \mathrm{pH} \mathrm{8.0.} \mathrm{The} \mathrm{concen-}$ tration of the protein was measured using the Pierce BCA Protein Assay Kit (Thermo Scientific, Beijing, People's Republic of China). The final protein preparation was immediately used for crystallization screening at concentrations of 5 and $10 \mathrm{mg} \mathrm{ml}^{-1}$.

\subsection{Protein crystallization and data collection}

Screening for crystallization conditions was carried out by mixing $1 \mu \mathrm{l}$ protein solution with $1 \mu \mathrm{l}$ reservoir solution and equilibrating against $100 \mu \mathrm{l}$ reservoir solution in 48-well double-sample sittingdrop crystallization plates (XtalQuest, Beijing, People's Republic of China). All crystallization attempts were performed at $291 \mathrm{~K}$ using the sitting-drop vapour-diffusion method. Crystal Screen, Crystal Screen 2 and Index (Hampton Research, California, USA) were used for crystallization trials. Crystals of good quality were obtained in a condition consisting of $5 \%(v / v)$ Tacsimate, $0.1 M$ HEPES $\mathrm{pH} 7.0$, $10 \%(w / v)$ polyethylene glycol monomethyl ether 5000 .

For data collection, a single crystal was picked up using a nylon loop, immersed into a cryoprotectant solution consisting of the reservoir solution with $20 \%$ glycerol for about $30 \mathrm{~s}$ and flash-cooled at $100 \mathrm{~K}$. Diffraction data were collected using synchrotron radiation on beamline BL-5A (wavelength $1.0000 \AA$ ) at the Photon Factory, KEK, Japan. A total of 360 diffraction images were collected with an oscillation angle of $1^{\circ}$. Data were indexed, integrated and scaled

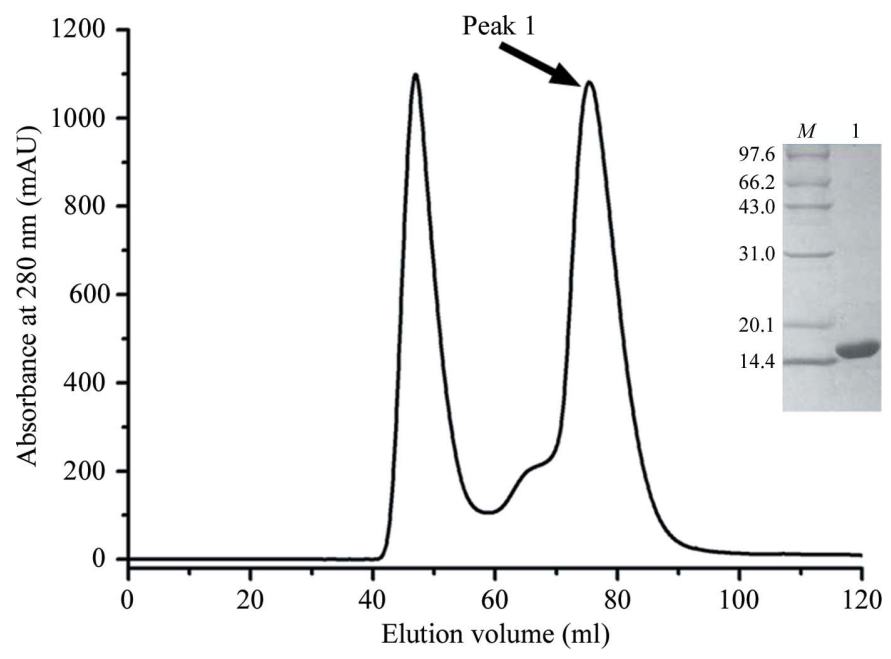

Figure 1

Purification of the nectin- $4 \mathrm{v}$ protein by gel filtration. A typical separation profile of nectin-4v on a Superdex 75 (HiLoad 16/60) column is shown. Proteins with an elution volume of $75.4 \mathrm{ml}$ were collected and analyzed by $15 \%$ SDS-PAGE (inset). Lane $M$, standard protein molecular-weight markers (labelled in $\mathrm{kDa}$ ); lane 1, peak 1. 


\section{crystallization communications}

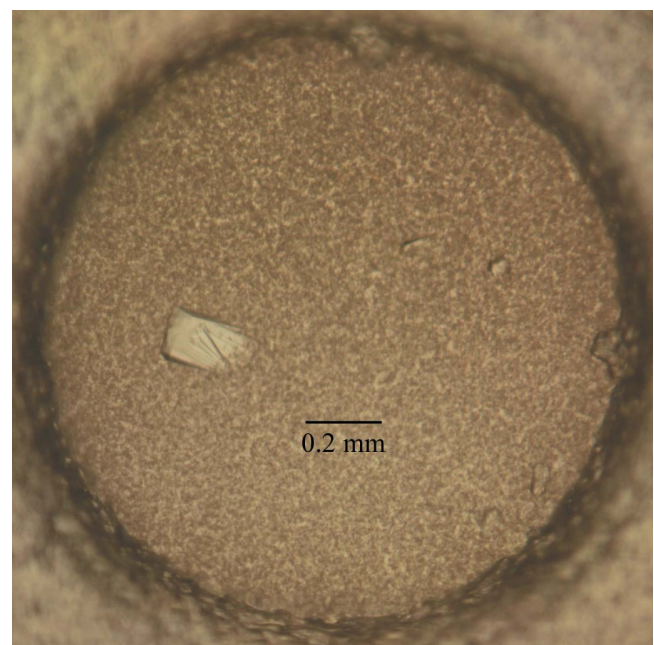

Figure 2

Representative crystal of the nectin- $4 \mathrm{v}$ protein. The dimensions of the crystal are about $0.2 \times 0.1 \times 0.04 \mathrm{~mm}$.

using DENZO and SCALEPACK as implemented in $H K L-2000$ (Otwinowski \& Minor, 1997). Detailed statistics are summarized in Table 1.

\section{Results and discussion}

The human nectin- 4 protein contains one IgV-like and two IgC-like domains in its extracellular region. The IgV-like domain of nectin-4 (nectin-4v) roughly spans Glu32-Pro145. This V-domain protein was expressed as a recombinant protein with a C-terminal hexahistidine tag in E. coli and was further purified by affinity and gel-filtration chromatography. As shown in Fig. 1, nectin-4v eluted as a symmetric peak at about $75.4 \mathrm{ml}$ on a Superdex 75 column, corresponding to a protein with a molecular weight of about $15 \mathrm{kDa}$. Therefore, nectin$4 \mathrm{v}$ exists mainly as a monomer in solution. The final purity of nectin$4 \mathrm{v}$ was demonstrated to be greater than $99 \%$ on $15 \%$ SDS-PAGE (Fig. 1). The yield of pure nectin- $4 \mathrm{v}$ protein was about $15 \mathrm{mg}$ per litre of cell culture.
Table 1

Data-collection statistics.

Values in parentheses are for the outermost resolution shell.

\begin{tabular}{ll}
\hline Space group & $P 2_{1}$ \\
Unit-cell parameters & \\
$\quad a(\AA)$ & 33.1 \\
$b(\AA)$ & 51.7 \\
$\quad c(\AA)$ & 56.9 \\
$\beta\left(\left(^{\circ}\right)\right.$ & 94.7 \\
Wavelength $(\AA)$ & 1.00000 \\
Resolution range $(\AA)$ & $50.00-1.80(1.86-1.80)$ \\
No. of observed reflections & 128137 \\
No. of unique reflections & 17741 \\
Completeness $(\%)$ & $100.0(100.0)$ \\
Multiplicity & $7.2(7.2)$ \\
$R_{\text {merge }} \dagger(\%)$ & $0.085(0.406)$ \\
Average $I / \sigma(I)$ & $23.2(5.1)$ \\
\hline
\end{tabular}

$\dagger R_{\text {merge }}=\sum_{h k l} \sum_{i}\left|I_{i}(h k l)-\langle I(h k l)\rangle\right| / \sum_{h k l} \sum_{i} I_{i}(h k l)$, where $\langle I(h k l)\rangle$ is the mean intensity of reflection $I(h k l)$ and $I_{i}(h k l)$ is the intensity of an individual measurement of reflection $I(h k l)$.

The initial crystallization screening trials for nectin- $4 \mathrm{v}$ were carried out using kits from Hampton Research. The purified protein could easily be crystallized and protein crystals were obtained within a week at $291 \mathrm{~K}$ under several conditions. Good-quality crystals were finally selected from a condition consisting of $5 \%(v / v)$ Tacsimate, $0.1 M$ HEPES $\mathrm{pH} 7.0,10 \%(w / v)$ polyethylene glycol monomethyl ether 5000. A crystal of about $0.2 \times 0.1 \times 0.04 \mathrm{~mm}$ in size (Fig. 2) diffracted to $1.8 \AA$ resolution (Fig. 3). The data-processing statistics are summarized in Table 1 . The space group of the crystal was $P 2_{1}$ and the unit-cell parameters were $a=33.1, b=51.7, c=56.9 \AA$, $\beta=94.7^{\circ}$. Overall, the diffraction data were of good quality, with an $R_{\text {merge }}$ of only about 0.085 for all resolution shells from 50.0 to $1.80 \AA$. The Matthews coefficient (Matthews, 1968) for the crystal was calculated to be $1.89 \AA^{3} \mathrm{Da}^{-1}$, with an estimated solvent content of about $35.0 \%$, which corresponds to two nectin- $4 \mathrm{v}$ molecules in the asymmetric unit. Nevertheless, the self-rotation function [generated by POLARRFN (Winn et al., 2011) using data from 12 to $5 \AA$ resolution with an integration radius of $30 \AA$ ] did not show any sign of twofold noncrystallographic symmetry. The largest off-origin peak in the native Patterson was $8.65 \%$ of the height of the origin peak, which suggested no significant pseudo-translation. We managed to determine the structure of nectin-4v with MOLREP (Vagin \& Teplyakov,

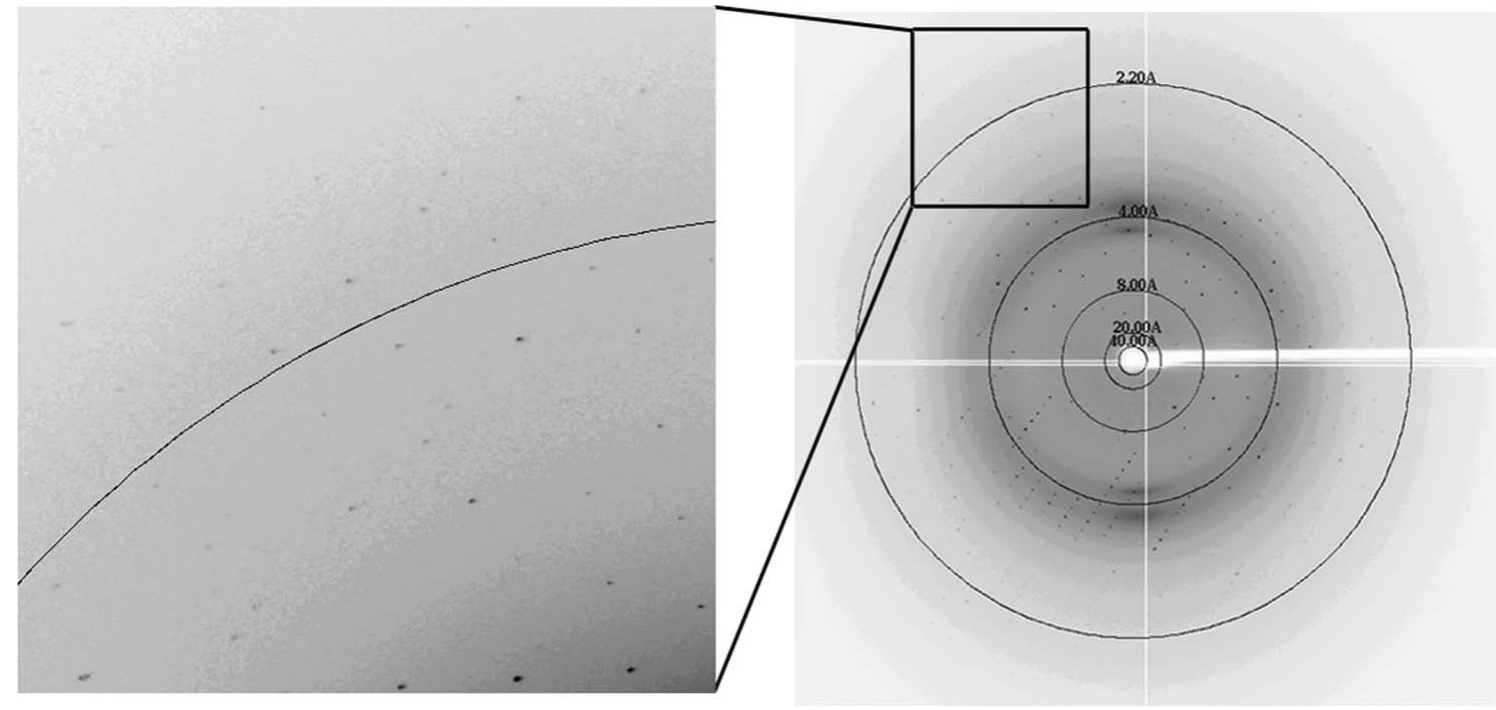

Figure 3

A representative diffraction image collected from a nectin- $4 \mathrm{v}$ crystal. The resolution shells are shown. 
2010) using the coordinates of nectin-1 residues 35-144 (PDB entry 3u83; Zhang et al., 2011) as the search model and we indeed found two molecules in the asymmetric unit. The $R$ factor after the translation function was 0.618 . The final nectin- $4 \mathrm{v}$ model has been refined to $R_{\text {work }}=0.1915$ and $R_{\text {free }}=0.2398$. Further refinement and structural analysis are currently under way.

This work was completed in the laboratory of Professor George F. Gao at the Institute of Microbiology, Chinese Academy of Sciences (IMCAS). We thank Dr Jianxun Qi for help with the collection and processing of the X-ray data.

\section{References}

Derycke, M. S., Pambuccian, S. E., Gilks, C. B., Kalloger, S. E., Ghidouche, A., Lopez, M., Bliss, R. L., Geller, M. A., Argenta, P. A., Harrington, K. M. \& Skubitz, A. P. (2010). Am. J. Clin. Pathol. 134, 835-845.

Fabre-Lafay, S. et al. (2007). BMC Cancer, 7, 73.

Fuchs, A. \& Colonna, M. (2006). Semin. Cancer Biol. 16, 359-366.

Matthews, B. W. (1968). J. Mol. Biol. 33, 491-497.

Mühlebach, M. D. et al. (2011). Nature (London), 480, 530-533.
Noyce, R. S., Bondre, D. G., Ha, M. N., Lin, L.-T., Sisson, G., Tsao, M.-S. \& Richardson, C. D. (2011). PLoS Pathog. 7, e1002240.

Otwinowski, Z. \& Minor, W. (1997). Methods Enzymol. 267, 307326.

Reymond, N., Fabre, S., Lecocq, E., Adelaïde, J., Dubreuil, P. \& Lopez, M. (2001). J. Biol. Chem. 276, 43205-43215.

Takahashi, K., Nakanishi, H., Miyahara, M., Mandai, K., Satoh, K., Satoh, A., Nishioka, H., Aoki, J., Nomoto, A., Mizoguchi, A. \& Takai, Y. (1999). J. Cell Biol. 145, 539-549.

Takai, Y., Ikeda, W., Ogita, H. \& Rikitake, Y. (2008). Annu. Rev. Cell Dev. Biol. 24, 309-342.

Takai, Y., Irie, K., Shimizu, K., Sakisaka, T. \& Ikeda, W. (2003). Cancer Sci. 94, 655-667.

Takai, Y. \& Nakanishi, H. (2003). J. Cell Sci. 116, 17-27.

Takano, A., Ishikawa, N., Nishino, R., Masuda, K., Yasui, W., Inai, K., Nishimura, H., Ito, H., Nakayama, H., Miyagi, Y., Tsuchiya, E., Kohno, N., Nakamura, Y. \& Daigo, Y. (2009). Cancer Res. 69, 6694-6703.

Vagin, A. \& Teplyakov, A. (2010). Acta Cryst. D66, 22-25.

Winn, M. D. et al. (2011). Acta Cryst. D67, 235-242.

Zhang, P., Mueller, S., Morais, M. C., Bator, C. M., Bowman, V. D., Hafenstein, S., Wimmer, E. \& Rossmann, M. G. (2008). Proc. Natl Acad. Sci. USA, 105, 18284-18289.

Zhang, N., Yan, J., Lu, G., Guo, Z., Fan, Z., Wang, J., Shi, Y., Qi, J. \& Gao, G. F. (2011). Nature Commun. 2, 577. 